\title{
Correction to: High incidence of invasive fungal infection during acute myeloid leukemia treatment in a resource-limited country: clinical risk factors and treatment outcomes
}

\author{
Variya Nganthavee ${ }^{1} \cdot$ Woraphun Phutthasakda ${ }^{1} \cdot$ Kawita Atipas $^{1} \cdot$ Sirikul Tanpong $^{1} \cdot$ Teeramet Pungprasert $^{1}$. \\ Dhanach Dhirachaikulpanich ${ }^{1}$. Saran Krithin ${ }^{1}$. Supang Tanglitanon ${ }^{1}$ - Warissara Jutidamrongphan ${ }^{1}$. \\ Weerapat Owattanapanich ${ }^{2} \cdot$ Methee Chayakulkeeree $^{3} \cdot$ Ployploen Phikulsod $^{2}$ [D
}

Published online: 18 June 2019

(C) Springer-Verlag GmbH Germany, part of Springer Nature 2019

\section{Correction to: Supportive Care in Cancer} https://doi.org/10.1007/s00520-019-04720-5

The name of Warissara Jutidamrongphan was incorrectly captured in the original manuscript. The name of Warissara Jutidamrongphan is now corrected.

Publisher's note Springer Nature remains neutral with regard to jurisdictional claims in published maps and institutional affiliations.

The online version of the original article can be found at https://doi.org/ $10.1007 / \mathrm{s} 00520-019-04720-5$

Ployploen Phikulsod

ployploen.phi@mahidol.ac.th

1 Department of Medicine, Faculty of Medicine Siriraj Hospital, Mahidol University, Bangkok, Thailand

2 Division of Hematology, Department of Medicine, Faculty of Medicine Siriraj Hospital, Mahidol University, 2 Wanglang Road, Bangkoknoi, Bangkok 10700, Thailand

3 Division of Infectious Diseases and Tropical Medicine, Department of Medicine, Faculty of Medicine Siriraj Hospital, Mahidol

University, Bangkok, Thailand 